\title{
Estudos empíricos da ironia: revisão sistemática e implicações para uma análise funcional
}

\section{Estudios empíricos de la ironía: revisión sistemática e implicaciones para un análisis funcional \\ Empirical Studies of Irony: Systematic Review and Implications for a functional Analysis}

\author{
Luciana Chequer Saraiva Messa* \\ Universidade Federal do Espírito Santo \\ Elizeu Borloti \\ Universidade Federal do Espírito Santo \\ Verônica Bender Haydu \\ Universidade Estadual de Londrina
}

Doi: https://doi.org/10.12804/revistas.urosario.edu.co/apl/a.6132

\begin{abstract}
Resumo
A ironia é um operante verbal sob controle múltiplo e, portanto, complexo, com a função de deixar o ouvinte produzir uma resposta, em geral contrária ao que foi dito e quase sempre com função de ridicularização. O objetivo deste artigo foi, a partir de uma revisão sistemática da literatura, mapear as variáveis (ou seus indicadores) estudadas em pesquisas empíricas e indicar elementos essenciais para a análise funcional da ironia. Buscas realizadas nas bases de dados BVS, NCBI, Science Direct, PsycInfo e Ebsco, feitas por meio dos descritores ironia, ironia verbal, sarcasmo, controle múltiplo, irônico e comportamento verbal, localizaram 43 artigos
\end{abstract}

em Psicologia, Linguística e Neurociência. Verificou-se que na análise funcional da ironia deve-se atentar às: (a) características dos integrantes do episódio verbal irônico e dos eventos antecedentes e consequentes da ironia; e (b) consequências das variáveis ambientais que controlam a ironia em diferentes nuances, como humor, sarcasmo, cinismo ou deboche. A descrição desses elementos em outras abordagens teóricas pode ser útil para uma análise funcional da ironia e contribuir para o conhecimento e para pesquisas experimentais na análise do comportamento.

Palavras-chave: ironia, análise do comportamento, análise funcional, comportamento verbal.

* Dirigir correspondencia a Luciana Chequer Saraiva Messa: Universidade Federal do Espírito Santo, Brasil. Correio eletrônico: lucianasmessa@gmail.com

Para citar este artigo: Messa, L. C. S., Borloti, E., \& Haydu, V. B. (2020). Estudos empíricos da ironia: revisão sistemática e implicações para uma análise funcional. Avances en Psicología Latinoamericana, 38(1), 218-236. https://doi.org/10.12804/ revistas.urosario.edu.co/apl/a.6132 


\section{Resumen}

La ironía es un operante verbal bajo control múltiple y, por lo tanto, complejo, con la función de dejar al oyente producir una respuesta, en general contraria a lo que fue dicho, y casi siempre con función de ridiculización. El objetivo de este artículo es, a partir de una revisión sistemática de la literatura, mapear las variables (o sus indicadores) estudiadas en investigaciones empíricas e indicar elementos esenciales para el análisis funcional de la ironía. Búsquedas en las bases de datos BVS, NCBI, Science Direct, PsycInfo y Ebsco, hechas por medio de los descriptores ironía, ironía verbal, sarcasmo, control múltiple, irónico y comportamiento verbal, localizaron 43 artículos en Psicología, Lingüística y Neurociencia. Se verificó que en el análisis funcional de la ironía se debe atentar a las: (a) características de los integrantes del episodio verbal irónico y de los eventos antecedentes y consecuentes de la ironía; y (b) consecuencias de las variables ambientales que controlan la ironía en diferentes matices, como humor, sarcasmo, cinismo o burla. La descripción de estos elementos en otros abordajes teóricos puede ser útil para un análisis funcional de la ironía y contribuir para el conocimiento y para investigaciones experimentales en el análisis del comportamiento.

Palabras clave: ironía, análisis del comportamiento, análisis funcional, comportamiento verbal.

\section{flbstract}

The irony is a verbal operant under multiple control, therefore, complex, with the function of letting the listener produce a response, usually contrary to what has been said and almost always with the purpose of ridicule. The objective of this article is, from a systematic review of literature, to map the variables (or their indicators) being studied in empiric researches and indicate essential elements for a functional analysis of irony. A search in the data bases BVS, NCBI, Science Direct, PsycInfo e Ebsco, using the keywords: irony, verbal irony, sarcasm, multiple control, autoclitics, and ironical and verbal behavior, produced 43 articles in psychology, linguistics or neuroscience. It was verified that in the functional analysis of irony the analyst should be aware of: (a) the characteristics of the members of the ironical verbal episode and the antecedents and consequents events of irony, and (b) consequences of the environmental variables that controls irony as humor, sarcasm, cynicism, or debauchery. The description of these empiric elements in other theoretical approaches can be useful for functional analysis of irony and contribute to the knowledge and to the experimental researches about this in behavior analysis.

Keywords: Irony, behavior analysis, functional analysis, verbal behavior.

O livro Verbal Behavior (Skinner, 1957) é o marco teórico da explicação do comportamento verbal na análise do comportamento. Um programa de estudos foi apresentado por seu autor para uma análise funcional do comportamento verbal que muito contribuiu para o avanço dos estudos atuais desse repertório. Skinner propôs esse programa a partir da definição de comportamento verbal (operante mediado por um ouvinte qualificado, cujas consequências contribuem para a sua manutenção) e de sua classificação (primários e secundários, e seus subtipos funcionais). Tal classificação permitiu a identificação dos controles dos operantes verbais (únicos, múltiplos ou estendidos) e do papel da audiência na sua mediação com o ambiente, provendo seu reforço.

Diversos artigos de revisão sistemática da literatura realizados por analistas do comportamento já se ocuparam de descrever estudos empíricos gerados pelo Verbal Behavior. Independentemente de esses estudos serem focados em operantes verbais em geral (e.g., Eikeseth, \& Smith, 2013; Gross, Fuqua, \& Merritt, 2013; Kisamore, Karsten, Mann, \& Conde, 2013) ou em operantes verbais específicos (e.g., Anastácio-Pessana, Almeida-Verdu, Bevilacqua, \& Souza, 2015; Hübner, Austin, \& Miguel, 2008; Koehler-Platten, Grow, Schulze, \& Bertone, 2013), eles sempre têm o objetivo de apontar os 
elementos para a análise funcional empírica, e não apenas interpretativa, do comportamento verbal. Entretanto, há uma carência de revisões de estudos empíricos sobre comportamentos verbais em outras áreas do conhecimento que não a análise do comportamento, cujos achados possam contribuir para a análise funcional da linguagem.

Para a análise funcional do comportamento, tanto o verbal quanto o não verbal, Skinner (2003) propôs um argumento fundamental:

As variáveis externas das quais o comportamento é função dão margem ao que pode ser chamado de análise causal ou funcional. Tentamos prever e controlar o comportamento de um organismo individual. Esta é a nossa "variável dependente" - o efeito para o qual procuramos a causa. Nossas “variáveis independentes" - as causas do comportamento - são as condições externas das quais o comportamento é função. Relações entre as duas - as relações de "causa e efeito" no comportamento - são as leis de uma ciência (p. 38).

Portanto, a avaliação das contingências envolvendo uma ação verbal de um indivíduo é fundamental para que se possa fazer uma análise funcional dessa ação. Isso significa que características das variáveis que envolvem os estímulos antecedentes (ocasião em que a resposta ocorre), a resposta verbal em si e suas consequências reforçadoras, mediadas por uma audiência, devem ser a base para a análise funcional (i.e., empírica) no sentido do argumento skinneriano, destacado na citação apresentada no parágrafo anterior.

Em defesa desse argumento, o presente artigo de revisão sistemática da literatura foca na análise empírica do comportamento verbal irônico feita em estudos empíricos em outras áreas do conhecimento que não a análise do comportamento, de modo a identificar funções da ironia nos dados desses estudos. A análise aqui proposta foi feita considerando a ironia, de acordo com os princípios da análise do comportamento, como sendo
[...] a verbal behaviour under multiple controls: Multiple audience, stimuli (especially non-verbal) and motivational operations from these stimuli and multiple audiences with the function of letting the listener produce a response (in general contrary to what was said and almost always with ridiculous appointment) ${ }^{1}$ (Messa, Borloti, \& Carmelino, 2014, p. 117).

Uma análise com o foco destacado no parágrafo anterior tem seu mérito social, dada a função do comportamento verbal irônico estar diretamente relacionada à vida em sociedade. A emissão e a manutenção da ironia são vantajosas não apenas para o falante, mas também para o ouvinte. Isso significa, por exemplo, que a ironia pode ser emitida em um único contexto, tendo em vista dois efeitos diferentes: ridicularizar e fazer rir (humor). Esses aspectos dependerão de alguns fatores: (a) quem é o falante; (b) quem é (são) o(s) ouvinte(s). Uma pessoa que emite ironia com o objetivo de ridicularizar alguém pode sentir o efeito humorístico da ironia em si mesmo; então, o efeito pode ser punitivo para quem ouve (vítima) e de humor para quem o fez (falante). Essa é uma parte da complexidade da ironia.

Diferentemente da mentira, por exemplo, em que o objetivo pode ser apenas se esquivar da punição, a ironia tem um rol de possibilidades, tanto de causas quanto de efeitos. No caso de a ironia ter função de humor, ela pode fazer com que o ouvinte ria e amenize as contingências aversivas do contexto (Hübner, Miguel, \& Michael, 2005). Emitir ironia e reagir a ela com essa vantagem ou com outras, está diretamente relacionado a dois aspectos que Skinner (2003) apontou com relação ao comportamento operante em geral: frequência

[...] um comportamento verbal sob múltiplos controles: audiência múltipla, estímulos (especialmente não verbais) e operações motivacionais advindas desses estímulos e audiência múltipla, com a função de deixar o ouvinte produzir uma resposta (em geral contrária ao que foi dito e quase sempre com função de ridicularização). 
e probabilidade da emissão de acordo com a taxa de reforço.

Com relação ao ouvinte, tem-se a mesma explicação: um ouvinte reage positivamente ou negativamente a uma ironia, respectivamente, como estímulo apetitivo ou aversivo. Como estímulo apetitivo tem-se o humorismo em geral. Como estímulo aversivo pode-se citar o seguinte exemplo: se um trabalhador costuma ouvir ironias sarcásticas (as com função de crítica e deboche) de um mesmo colega de trabalho com relação às suas competências profissionais, existe grande probabilidade de o comportamento dele diante desse colega de trabalho se manter por reforço negativo (fuga-esquiva). Além disso, existe também uma grande probabilidade de que a ironia do colega, emitida com intenção de criticar e debochar, elicie sentimentos negativos nesse trabalhador, que tenderá a se afastar ou a minimizar a aversão do colega irônico. Do ponto de vista prático, em geral, quando não é possível o afastamento da estimulação aversiva, reações negativas são minimizadas com piadas (Hübner et al., 2005). Assim, a relevância social do presente estudo se soma à científica, ao propor condições para melhorar o diálogo dos analistas do comportamento com outras áreas do conhecimento.

Analistas do comportamento não têm utilizado achados de outras áreas para o estudo da ironia; nem mesmo têm estudado o tema ironia especificamente e internamente à análise do comportamento (uma exceção é o artigo de Messa et al., 2014). O contrário ocorre na Linguística, área na qual o estudo da ironia é comum, devido às suas variadas faces (diferentes formas e funções da ironia), sendo elas o principal interesse de investigação nessa área (e.g., Brait, 1996; Machado, 1995; Nishiwaki, 2015). A partir de variados contextos de aprendizagem, gerando efeitos diversos, tanto de compreensão quanto de manipulação do episódio verbal, os linguistas, mesmo não usando termos analítico-comportamentais, têm apontado o "poder" que a ironia pode gerar pelos efeitos que produz, que podem variar do reforço positivo (e.g., "ganhos") para ambas as partes do episódio (falante e ouvinte) ao controle aversivo, em geral, do comportamento do ouvinte.

$\mathrm{O}$ conceito de ironia foi estudado a fundo por Paiva (1961), definindo-a como aquilo que é o contrário do que se diz, e ampliando o conceito em cinco subtipos de ironias, a partir dessa definição básica. Os cinco subtipos são: ironia pura, satírica, disfemística, restritiva e contornante. A ironia pura ocorre quando a função verbal é produzir como efeito apenas a compreensão do contrário do que se diz. A satírica é quando se produz como consequência a ridicularização pelo cômico. A disfemística é a ironia com a função de ridicularizar pelo menosprezo. Na restritiva, a função é a de ridicularizar pela restrição e na contornante, pela indiferença. As funções que os diferentes subtipos de ironia têm sobre o comportamento do ouvinte suscita a importância de análises dos efeitos das consequências, de tal forma a justificar a análise funcional da ironia pela ótica da análise do comportamento. Assim, o objetivo deste artigo foi, a partir de uma revisão sistemática da literatura, mapear as variáveis (ou indicadores de variáveis) que estão sendo estudadas pelas pesquisas empíricas sobre ironia em outras áreas e indicar elementos essenciais para a análise funcional da ironia.

\section{Método}

A seleção das fontes de dados para a revisão partiu da definição de estudo empírico de Demo (2000), em que o estudo selecionado deveria ser o que mostra a "face empírica e fatual da realidade; produz e analisa dados, procedendo sempre pela via do controle empírico e fatual" (p. 21). Nessa definição de empírico, delimitaram-se quais aspectos dos estudos de outras áreas poderiam interessar em uma análise funcional, no sentido skinneriano. Esses aspectos são os mesmos pontos centrais da análise funcional da pesquisa comportamental tradicional: previsão de resposta a partir da ocorrência de variáveis 
específicas e confirmação dessa ocorrência nos dados, o repertório do participante.

Assim, na busca dos elementos úteis à análise funcional na bibliografia de outras áreas que não a análise do comportamento foram estabelecidas como categorias de análise: (a) conceito de ironia; (b) características dos participantes; (c) objetivo da análise da ironia (produção, compreensão ou ambas); (d) tipo de estímulos discriminativos para a produção e/ou compreensão da ironia (e.g., sentenças, situações, histórias); e (e) resultados, efeitos ou consequências obtidos (as). Essas categorias foram tidas como úteis por poderem indicar itens da tríplice contingência, contribuindo para uma análise funcional do comportamento verbal irônico.

\section{Fontes de Dados e Procedimento}

Os descritores selecionados para a busca de artigos foram: ironia, ironia verbal, sarcasmo, controle múltiplo, irônico e comportamento verbal (irony, verbal irony, sarcasm, multiple control, ironic, verbal behavior). Inicialmente eles foram combinados um a um ou uns aos outros por interseção pelo operador booleano and. Cada descritor foi localizado individualmente até se esgotar a necessidade de localização daquele termo; só então foi utilizado um novo descritor para a busca de novos artigos. Em seguida, realizou-se uma busca com os operadores booleanos de combinação de termos por união (or) e, depois, por exclusão (not).

Tanto na bibliografia da análise do comportamento quanto na das outras áreas, a localização dos artigos ocorreu por meio das bases de busca e recuperação disponíveis via Internet e dos descritores citados anteriormente. A busca foi realizada nas bases de dados da Biblioteca Virtual em Saúde (BVS), da National Center for Biotechnology Information (NCBI); da Science Direct, da PsycInfo e da EBSCO, sem restrição do período de busca. A partir de uma busca prévia, estas bases de dados foram escolhidas em função da quantidade e quali- dade de estudos sobre o tema nas áreas específicas (Linguística, Psicologia e Neurociência) indexados nas mesmas. A localização dos artigos foi realizada de maneira livre, ou seja, o trabalho foi localizado e separado de acordo com os descritores indicados, independentemente da localização deles no texto (se no resumo, no título ou no corpo do texto).

Os critérios de inclusão dos artigos foram: (a) palavra ironia estar em qualquer lugar no texto, (b) serem estudos de natureza empírica, e (c) os estudos serem das áreas de Psicologia, Linguística e Neurociência. Os critérios de exclusão foram: (a) artigos abordarem a ironia como previsão situacional (a famosa "ironia do destino"); (b) artigos serem da Medicina (que, em geral, objetivaram mapear o funcionamento cerebral enquanto pessoas ouvem ironias); e (c) artigos conterem explicações psicanalíticas, filosóficas ou literárias da ironia.

A análise dos resultados foi realizada a partir da leitura inicial do resumo do artigo para confirmação da seleção dentro dos critérios anteriormente descritos. Em seguida foi feita a leitura do artigo na íntegra e registradas as seguintes informações: autores, ano de publicação, características dos participantes. Dado o contexto de análise da ironia em cada artigo, foram registrados: os objetivos dos estudos, os tipos de antecedentes utilizados pelos autores (estímulo discriminativo), o tipo de efeito (consequência) e o foco da análise, isto é, se a compreensão (com especificação das características do ouvinte) ou a produção da ironia (com especificação das características do falante). Depois de registradas, essas informações (dados) foram organizadas em uma planilha em ordem alfabética, a partir dos nomes dos autores.

\section{Resultados e discussão}

A partir da busca feita nas bases de dados foram encontrados 211 artigos. Desse total, com base na leitura dos títulos dos artigos e aplicando-se os critérios especificados no método, foram excluídos, 
inicialmente, 167. A partir da leitura dos resumos dos artigos e com a aplicação dos critérios de inclusão, foram selecionados os 43 artigos dos quais os dados estão organizados na tabela 1 .

Os artigos analisados são em sua maioria, da Psicologia (33). Em seguida, são os da Neurociência (6) e da Linguística (4). O foco dos estudos foi, em grande parte, a análise da compreensão da ironia; alguns analisaram tanto as condições de compreensão quanto as de produção da ironia em contextos que permitiam ao participante ver, ouvir ou ler situações em que tipos diferentes de ironia estavam presentes em frases/sentenças e/ou em situações do cotidiano. Esses contextos tiveram função de estímulos antecedentes (discriminativos) para emissão da compreensão ou para estimular a emissão de uma resposta irônica pelo participante.

Os estudos analisados eram bastante diversificados em seus objetivos gerais, alguns deles se propuseram a investigar: (a) os efeitos emocionais que a ironia gera nos ouvintes em situações distintas, por exemplo, em situações comunicativas complexas, em relações familiares e não familiares, bem como a função social do uso da ironia (Akimoto \& Miyazawa, 2011; Amenta et al., 2013; Campanella, 2013; Dennis et al., 2012; Filik et al., 2015; Filik et al., 2016); e (b) a produção e compreensão de crianças quando expressões irônicas são utilizadas em situações comunicativas familiares (Angeleri, \& Airenti, 2014; Filik et al., 2014; Recchia et al., 2010).

Quanto ao que concluíram, alguns estudos demonstraram que a emissão de ironia vem acompanhada de "pistas" verbais e não verbais emitidas pelo falante com a função de se fazer compreender pelos ouvintes (Anolli et al., 2000; Baptista et al., 2015; Bruntsch, \& Ruch, 2017a). Outros, que a ironia é uma forma de comunicação prevalecente entre adolescentes usuários de substâncias psicoativas com função de aproximação social e humor (Brum, $\&$ Siniak, 2011). Alguns estudos apresentaram dados que demonstram uma tendência ao uso de ironia por pessoas que costumam utilizar o humor com frequência (Calmus, \& Caillies, 2014; Dews et al., 1996; Jorgensen et al., 1984). Em outros, a compreensão do elogio irônico e seus benefícios além da crítica foram discutidos (Bruntsch, \& Ruch, 2017b; Dennis et al., 2012; Bruntsch, \& Ruch, 2017b). Adicionalmente, houve estudos que demonstraram que pessoas com determinados diagnósticos psiquiátricos compreendem observações irônicas, enquanto as com outros tipos mais graves de diagnóstico têm dificuldades em compreender essas observações.

Tabela 1.

Autores e ano, objetivo geral, número de participantes, características dos participantes, tipos de antecedentes $\left(S^{D}\right)$, tipo de efeito (consequências) da emissão de ironia e se envolvia compreensão elou produção da ironia (ouvinte elou falante) de acordo com as publicações revisadas

\begin{tabular}{|c|c|c|c|c|c|c|}
\hline Autores/ano & $\mathrm{N}$ & Objetivo geral & $\begin{array}{c}\text { Características } \\
\text { dos } \\
\text { participantes }\end{array}$ & $\begin{array}{c}\text { Tipo de } \\
\text { antecedente } \\
\left(\mathrm{S}^{\mathrm{D}}\right)\end{array}$ & Tipo de efeito & $\begin{array}{c}\text { Compreensão } \\
\text { ou produção } \\
\text { da ironia }\end{array}$ \\
\hline $\begin{array}{l}\text { Akimoto, \& } \\
\text { Miyazawa } \\
(2011)\end{array}$ & 30 & $\begin{array}{l}\text { Investigar que fatores } \\
\text { desempenham um papel nos } \\
\text { sentimentos de um ouvinte } \\
\text { evocados pela ironia. }\end{array}$ & Adultos típicos & $\begin{array}{l}\text { Sentenças } \\
\text { positivas }\end{array}$ & $\begin{array}{l}\text { Risada, prazer e } \\
\text { humor }\end{array}$ & Compreensão \\
\hline $\begin{array}{l}\text { Amenta, Noël, } \\
\text { Verbanck, \& } \\
\text { Campanella } \\
(2013)\end{array}$ & 44 & $\begin{array}{l}\text { Decodificar componentes } \\
\text { emocionais em situações } \\
\text { comunicativas complexas } \\
\text { (efeito emocional da ironia) e } \\
\text { sua relação com habilidades } \\
\text { empáticas em alcoolistas } \\
\text { crônicos. }\end{array}$ & Adultos típicos & $\begin{array}{l}\text { Sentenças } \\
\text { positivas }\end{array}$ & $\begin{array}{l}\text { Convencimento } \\
\text { e atenção }\end{array}$ & Compreensão \\
\hline
\end{tabular}




\begin{tabular}{|c|c|c|c|c|c|c|}
\hline Autores/ano & $\mathrm{N}$ & Objetivo geral & $\begin{array}{l}\text { Características } \\
\text { dos } \\
\text { participantes }\end{array}$ & $\begin{array}{c}\text { Tipo de } \\
\text { antecedente } \\
\left(\mathrm{S}^{\mathrm{D}}\right)\end{array}$ & Tipo de efeito & $\begin{array}{l}\text { Compreensão } \\
\text { ou produção } \\
\text { da ironia }\end{array}$ \\
\hline $\begin{array}{l}\text { Angeleri, \& } \\
\text { Airenti (2014) }\end{array}$ & 100 & $\begin{array}{l}\text { Investigar se crianças } \\
\text { mostram um entendimento } \\
\text { anterior de expressões } \\
\text { irônicas em situações } \\
\text { comunicativas familiares, } \\
\text { e investigar relações entre } \\
\text { habilidades de compreensão, } \\
\text { linguagem e teoria da mente. }\end{array}$ & $\begin{array}{l}\text { Crianças } \\
\text { típicas }\end{array}$ & $\begin{array}{l}\text { Situações } \\
\text { cotidianas }\end{array}$ & $\begin{array}{l}\text { Convencimento } \\
\text { e atenção/ } \\
\text { risada, prazer e } \\
\text { humor }\end{array}$ & Compreensão \\
\hline $\begin{array}{l}\text { Anolli, Ciceri, } \\
\text { \& Infantino } \\
(2000)\end{array}$ & 50 & $\begin{array}{l}\text { Analisar as funções sociais } \\
\text { da ironia e seus efeitos sobre } \\
\text { adultos. }\end{array}$ & Adultos típicos & $\begin{array}{l}\text { Sentenças } \\
\text { positivas }\end{array}$ & $\begin{array}{l}\text { Convencimento } \\
\text { e atenção/ } \\
\text { Risada, prazer } \\
\text { e humor/ } \\
\text { crítica, deboche, } \\
\text { constrangimento }\end{array}$ & Compreensão \\
\hline
\end{tabular}

\begin{tabular}{|c|c|c|c|c|c|c|}
\hline $\begin{array}{l}\text { Baptista, } \\
\text { Macedo, \& } \\
\text { Boggio }(2015)\end{array}$ & 20 & $\begin{array}{l}\text { Investigar por meio do } \\
\text { padrão de movimento dos } \\
\text { olhos como as pistas da } \\
\text { ironia são integradas diante } \\
\text { de declarações irônicas } \\
\text { e a maneira pela qual a } \\
\text { integração dessas pistas } \\
\text { pode afetar homens e } \\
\text { mulheres. }\end{array}$ & Adultos típicos & $\begin{array}{l}\text { Situações } \\
\text { cotidianas }\end{array}$ & $\begin{array}{l}\text { Convencimento } \\
\text { e atenção }\end{array}$ & $\begin{array}{l}\text { Compreensão/ } \\
\text { produção }\end{array}$ \\
\hline $\begin{array}{l}\text { Brum, \& } \\
\text { Siniak (2011) }\end{array}$ & 12 & $\begin{array}{l}\text { Compreender a comunicação } \\
\text { utilizada por adolescentes, } \\
\text { usuários de substâncias } \\
\text { psicoativas. }\end{array}$ & Adolescentes & $\begin{array}{l}\text { Sentenças } \\
\text { positivas }\end{array}$ & $\begin{array}{l}\text { Risada, prazer, } \\
\text { humor }\end{array}$ & Produção \\
\hline $\begin{array}{l}\text { Bruntsch, \& } \\
\text { Ruch (2017a) }\end{array}$ & 648 & $\begin{array}{l}\text { Avaliar quais traços de } \\
\text { personalidade relacionados } \\
\text { ao humor positivo ou } \\
\text { negativo podem prever o uso } \\
\text { da ironia. }\end{array}$ & Adultos típicos & $\begin{array}{l}\text { Sentenças } \\
\text { positivas e } \\
\text { negativas }\end{array}$ & $\begin{array}{l}\text { Risada, prazer } \\
\text { e humor/ } \\
\text { convencimento e } \\
\text { atenção }\end{array}$ & Compreensão \\
\hline $\begin{array}{l}\text { Bruntsch, \& } \\
\text { Ruch (2017b) }\end{array}$ & 153 & $\begin{array}{l}\text { Investigar se a compreensão } \\
\text { do elogio irônico pode } \\
\text { beneficar além de criticar. }\end{array}$ & Adultos típicos & $\begin{array}{l}\text { Situações } \\
\text { cotidianas }\end{array}$ & $\begin{array}{l}\text { Risada, prazer e } \\
\text { humor/ crítica, } \\
\text { deboche, } \\
\text { constrangimento }\end{array}$ & Compreensão \\
\hline $\begin{array}{l}\text { Caillies, } \\
\text { Bertot, Motte, } \\
\text { Raynaud, \& } \\
\text { Abely (2014) }\end{array}$ & 10 & $\begin{array}{l}\text { Investigar a dificuldade } \\
\text { de crianças com TDAH } \\
\text { compreenderem falsas } \\
\text { crenças de segunda ordem e } \\
\text { observações irônicas. }\end{array}$ & $\begin{array}{l}\text { Crianças } \\
\text { atípicas }\end{array}$ & $\begin{array}{l}\text { Situações } \\
\text { cotidianas }\end{array}$ & $\begin{array}{l}\text { Convencimento } \\
\text { e atenção }\end{array}$ & $\begin{array}{l}\text { Compreensão/ } \\
\text { produção }\end{array}$ \\
\hline $\begin{array}{l}\text { Caillies, Hody, } \\
\& \text { Calmus } \\
(2012)\end{array}$ & 2 & $\begin{array}{l}\text { Caracterizar as habilidades } \\
\text { pragmáticas de crianças } \\
\text { francesas com paralisia } \\
\text { cerebral, por meio da } \\
\text { compreensão da ironia e dos } \\
\text { estados mentais de outras } \\
\text { pessoas. }\end{array}$ & $\begin{array}{l}\text { Crianças } \\
\text { atípicas }\end{array}$ & $\begin{array}{l}\text { Situações } \\
\text { cotidianas }\end{array}$ & $\begin{array}{l}\text { Convencimento } \\
\text { e atenção }\end{array}$ & Compreensão \\
\hline
\end{tabular}




\begin{tabular}{|c|c|c|c|c|c|c|}
\hline Autores/ano & $\mathrm{N}$ & Objetivo geral & $\begin{array}{l}\text { Características } \\
\text { dos } \\
\text { participantes }\end{array}$ & $\begin{array}{c}\text { Tipo de } \\
\text { antecedente } \\
\left(\mathrm{S}^{\mathrm{D}}\right)\end{array}$ & Tipo de efeito & $\begin{array}{l}\text { Compreensão } \\
\text { ou produção } \\
\text { da ironia }\end{array}$ \\
\hline $\begin{array}{l}\text { Calmus, \& } \\
\text { Caillies (2014) }\end{array}$ & 30 & $\begin{array}{l}\text { Investigar se o grau } \\
\text { de contraste da ironia } \\
\text { está relacionado com o } \\
\text { humorístico percebido dos } \\
\text { comentários irônicos. }\end{array}$ & Adultos típicos & $\begin{array}{l}\text { Sentenças } \\
\text { positivas }\end{array}$ & $\begin{array}{l}\text { Risada, prazer e } \\
\text { humor }\end{array}$ & Compreensão \\
\hline $\begin{array}{l}\text { Cornejol, } \\
\text { Simonetti, } \\
\text { Aldunate, } \\
\text { Ibáñez, López, } \\
\& \text { Melloni } \\
(2007)\end{array}$ & 35 & $\begin{array}{l}\text { Avaliar se a indução de } \\
\text { estratégias holísticas } \\
\text { ou analíticas influencia } \\
\text { a compreensão e o } \\
\text { processamento de expressões } \\
\text { altamente contextualizadas } \\
\text { da linguagem comum. }\end{array}$ & Adultos típicos & $\begin{array}{l}\text { Situações } \\
\text { cotidianas }\end{array}$ & $\begin{array}{l}\text { Risada, prazer e } \\
\text { humor }\end{array}$ & $\begin{array}{l}\text { Compreensão/ } \\
\text { produção }\end{array}$ \\
\hline $\begin{array}{l}\text { Deliens et al. } \\
(2015)\end{array}$ & 30 & $\begin{array}{l}\text { Determinar se os } \\
\text { participantes privados de } \\
\text { sono são tão capazes como } \\
\text { participantes descansados } \\
\text { de adotar outra perspectiva } \\
\text { na avaliação de declarações } \\
\text { sarcásticas. }\end{array}$ & Adultos típicos & $\begin{array}{l}\text { Sentenças } \\
\text { negativas }\end{array}$ & $\begin{array}{l}\text { Crítica, } \\
\text { deboche e } \\
\text { constrangimento }\end{array}$ & $\begin{array}{l}\text { Compreensão/ } \\
\text { produção }\end{array}$ \\
\hline $\begin{array}{l}\text { Dennis et al. } \\
(2012)\end{array}$ & 71 & $\begin{array}{l}\text { Investigar compreensão } \\
\text { da crítica irônica e elogios } \\
\text { empáticos, em tarefa que } \\
\text { exige identificação da crença } \\
\text { e da intenção do falante em } \\
\text { conversas diretas e indiretas. }\end{array}$ & $\begin{array}{l}\text { Crianças } \\
\text { atípicas }\end{array}$ & $\begin{array}{l}\text { Situações } \\
\text { cotidianas }\end{array}$ & $\begin{array}{l}\text { Convencimento } \\
\text { e atenção }\end{array}$ & Compreensão \\
\hline $\begin{array}{l}\text { Dews et al. } \\
\text { (1996) }\end{array}$ & 224 & $\begin{array}{l}\text { Investigar a compreensão } \\
\text { da ironia e a sensibilidade à } \\
\text { mesquinharia e humor como } \\
\text { funções da ironia. }\end{array}$ & $\begin{array}{l}\text { Crianças / } \\
\text { típicas }\end{array}$ & $\begin{array}{l}\text { Sentenças } \\
\text { positivas e } \\
\text { negativas }\end{array}$ & $\begin{array}{l}\text { Risada, prazer e } \\
\text { humor/ crítica, } \\
\text { deboche, } \\
\text { constrangimento }\end{array}$ & Compreensão \\
\hline $\begin{array}{l}\text { Filik, Hunter, } \\
\text { \& Leuthold } \\
(2015)\end{array}$ & 48 & $\begin{array}{l}\text { Investigar o embotamento } \\
\text { da emoção examinando a } \\
\text { relação entre a compreensão } \\
\text { de um discurso escrito } \\
\text { irônico e da realização de } \\
\text { ações motoras relacionadas } \\
\text { ao afeto. }\end{array}$ & Adultos típicos & $\begin{array}{l}\text { Sentenças } \\
\text { positivas e } \\
\text { negativas }\end{array}$ & $\begin{array}{l}\text { Risada, prazer e } \\
\text { humor/ crítica, } \\
\text { deboche, } \\
\text { constrangimento }\end{array}$ & Compreensão \\
\hline $\begin{array}{l}\text { Filik, } \\
\text { Leuthold, } \\
\text { Wallington, \& } \\
\text { Page (2014) }\end{array}$ & 38 & $\begin{array}{l}\text { Investigar as diferenças no } \\
\text { processamento de ironias } \\
\text { familiares e não familiares. }\end{array}$ & Adultos típicos & $\begin{array}{l}\text { Sentenças } \\
\text { positivas }\end{array}$ & $\begin{array}{l}\text { Risada, prazer e } \\
\text { humor }\end{array}$ & Compreensão \\
\hline $\begin{array}{l}\text { Filik, Țurcan, } \\
\text { Thompson, } \\
\text { Harvey, Davies, } \\
\& \text { Turner (2016) }\end{array}$ & 144 & $\begin{array}{l}\text { Análise da compreensão do } \\
\text { sarcasmo e do seu impacto } \\
\text { emocional em adultos. }\end{array}$ & Adultos típicos & $\begin{array}{l}\text { Situações } \\
\text { cotidianas }\end{array}$ & $\begin{array}{l}\text { Convencimento } \\
\text { e atenção }\end{array}$ & Compreensão \\
\hline $\begin{array}{l}\text { Filippova, } \\
\text { \& Astington } \\
(2008)\end{array}$ & 96 & $\begin{array}{l}\text { Descrever o } \\
\text { desenvolvimento do } \\
\text { raciocínio social em crianças } \\
\text { em idade escolar durante } \\
\text { uma interação verbal. }\end{array}$ & $\begin{array}{l}\text { Crianças e } \\
\text { adultos/ típicos }\end{array}$ & $\begin{array}{l}\text { Sentenças } \\
\text { positivas }\end{array}$ & $\begin{array}{l}\text { Risada, prazer e } \\
\text { humor }\end{array}$ & $\begin{array}{l}\text { Compreensão/ } \\
\text { produção }\end{array}$ \\
\hline
\end{tabular}




\begin{tabular}{|c|c|c|c|c|c|c|}
\hline Autores/ano & $\mathrm{N}$ & Objetivo geral & $\begin{array}{l}\text { Características } \\
\text { dos } \\
\text { participantes }\end{array}$ & $\begin{array}{c}\text { Tipo de } \\
\text { antecedente } \\
\left(\mathrm{S}^{\mathrm{D}}\right)\end{array}$ & Tipo de efeito & $\begin{array}{c}\text { Compreensão } \\
\text { ou produção } \\
\text { da ironia }\end{array}$ \\
\hline $\begin{array}{l}\text { Filippova, } \\
\text { \& Astington } \\
(2010)\end{array}$ & $\begin{array}{l}72 \\
24\end{array}$ & $\begin{array}{l}\text { Analisar a compreensão de } \\
\text { aspectos sóciocognitivos e } \\
\text { sóciocomunicativos da ironia } \\
\text { no discurso de crianças } \\
\text { comparados com os de } \\
\text { adultos. }\end{array}$ & $\begin{array}{l}\text { Crianças/ } \\
\text { típicas/ } \\
\text { Adultos típicos }\end{array}$ & $\begin{array}{l}\text { Situações } \\
\text { cotidianas }\end{array}$ & $\begin{array}{l}\text { Risada, prazer e } \\
\text { humor }\end{array}$ & $\begin{array}{l}\text { Compreensão/ } \\
\text { produção }\end{array}$ \\
\hline $\begin{array}{l}\text { Gaudreau, } \\
\text { Monetta, } \\
\text { Macoir, } \\
\text { Laforce, } \\
\text { Poulin, \& } \\
\text { Hudon (2013) }\end{array}$ & 64 & $\begin{array}{l}\text { Examinar a compreensão da } \\
\text { ironia verbal em adultos com } \\
\text { e sem comprometimento } \\
\text { cognitivo leve. }\end{array}$ & $\begin{array}{l}\text { Adultos típicos } \\
\text { e atípicos }\end{array}$ & $\begin{array}{l}\text { Sentenças } \\
\text { positivas }\end{array}$ & $\begin{array}{l}\text { Convencimento } \\
\text { e atenção }\end{array}$ & Compreensão \\
\hline $\begin{array}{l}\text { Glenwright, \& } \\
\text { Pexman (2010) }\end{array}$ & 143 & $\begin{array}{l}\text { Investigar o desenvolvimento } \\
\text { da compreenção da diferença } \\
\text { entre ironia e sarcasmo. }\end{array}$ & $\begin{array}{l}\text { Crianças/ } \\
\text { típicas }\end{array}$ & $\begin{array}{l}\text { Sentenças } \\
\text { positivas e } \\
\text { negativas }\end{array}$ & $\begin{array}{l}\text { Risada, prazer e } \\
\text { humor }\end{array}$ & Compreensão \\
\hline $\begin{array}{l}\text { González- } \\
\text { Fuente, } \\
\text { Escandell- } \\
\text { Vidal, \& Prieto } \\
(2015)\end{array}$ & 46 & $\begin{array}{l}\text { Investigar as diferentes } \\
\text { formas de se compreender a } \\
\text { ironia. }\end{array}$ & Adultos típicos & $\begin{array}{l}\text { Situações } \\
\text { cotidianas }\end{array}$ & $\begin{array}{l}\text { Risada, prazer e } \\
\text { humor/ crítica, } \\
\text { deboche, } \\
\text { constrangimento/ } \\
\text { convencimento e } \\
\text { atenção }\end{array}$ & Compreensão \\
\hline $\begin{array}{l}\text { Hanke, \& Ibe } \\
(2016)\end{array}$ & 3 & $\begin{array}{l}\text { Análise da compreensão } \\
\text { de estruturas semânticas } \\
\text { conflituosas a partir de cenas } \\
\text { de um filme. }\end{array}$ & Adultos típicos & $\begin{array}{l}\text { Situações } \\
\text { cotidianas }\end{array}$ & $\begin{array}{l}\text { Convencimento } \\
\text { e atenção }\end{array}$ & Compreensão \\
\hline $\begin{array}{l}\text { Hur, \& Caixeta } \\
\text { (2013) }\end{array}$ & 2 & $\begin{array}{l}\text { Relatar linguagem não literal } \\
\text { (incluindo ironia) em casos } \\
\text { de demência semântica. }\end{array}$ & $\begin{array}{l}\text { Adultos } \\
\text { atípicos }\end{array}$ & $\begin{array}{l}\text { Sentenças } \\
\text { positivas }\end{array}$ & $\begin{array}{l}\text { Convencimento } \\
\text { e atenção }\end{array}$ & Compreensão \\
\hline $\begin{array}{l}\text { Ishida, \& Abe } \\
\text { (2010) }\end{array}$ & 2 & $\begin{array}{l}\text { Examinar se a vítima é } \\
\text { identificada na ironia por } \\
\text { menção ecóica. }\end{array}$ & Adultos típicos & $\begin{array}{l}\text { Situações } \\
\text { cotidianas }\end{array}$ & $\begin{array}{l}\text { Convencimento } \\
\text { e atenção }\end{array}$ & Compreensão \\
\hline $\begin{array}{l}\text { Jacob, } \\
\text { Kreifelts, } \\
\text { Nizielski, } \\
\text { Schütz, \& } \\
\text { Wildgruber } \\
(2016)\end{array}$ & 20 & $\begin{array}{l}\text { Examinar como as pistas } \\
\text { verbais e não verbais } \\
\text { da ironia são integradas } \\
\text { (compreendidas) } \\
\text { por percebedores (ouvintes). }\end{array}$ & Adultos típicos & $\begin{array}{l}\text { Sentenças } \\
\text { positivas e } \\
\text { negativas }\end{array}$ & $\begin{array}{l}\text { Crítica, } \\
\text { deboche e } \\
\text { constrangimento/ } \\
\text { risada, prazer e } \\
\text { humor }\end{array}$ & Compreensão \\
\hline $\begin{array}{l}\text { Jorgensen, } \\
\text { Miller, \& } \\
\text { Sperber (1984) }\end{array}$ & 24 & $\begin{array}{l}\text { Analisar se alunos de } \\
\text { graduação compreendem } \\
\text { sentenças com anedotas com } \\
\text { ironia quando omitidas dicas } \\
\text { ecoicas. }\end{array}$ & Adultos típicos & $\begin{array}{l}\text { Situações } \\
\text { cotidianas }\end{array}$ & $\begin{array}{l}\text { Convencimento } \\
\text { e atenção }\end{array}$ & Compreensão \\
\hline $\begin{array}{l}\text { Kreuz, \& Link } \\
(2002)\end{array}$ & 32 & $\begin{array}{l}\text { Investigar as assimetrias } \\
\text { (expectativas falhas) do uso } \\
\text { da ironia. }\end{array}$ & Adultos típicos & $\begin{array}{l}\text { Situações } \\
\text { cotidianas }\end{array}$ & $\begin{array}{l}\text { Convencimento } \\
\text { e atenção }\end{array}$ & Compreensão \\
\hline
\end{tabular}




\begin{tabular}{|c|c|c|c|c|c|c|}
\hline Autores/ano & $\mathrm{N}$ & Objetivo geral & $\begin{array}{l}\text { Características } \\
\text { dos } \\
\text { participantes }\end{array}$ & $\begin{array}{c}\text { Tipo de } \\
\text { antecedente } \\
\left(\mathrm{S}^{\mathrm{D}}\right)\end{array}$ & Tipo de efeito & $\begin{array}{l}\text { Compreensão } \\
\text { ou produção } \\
\text { da ironia }\end{array}$ \\
\hline $\begin{array}{l}\text { Kreuz, \& } \\
\text { Glucksberg } \\
\text { (1989) }\end{array}$ & 30 & $\begin{array}{l}\text { Investigar como os ouvintes } \\
\text { reconhecem o sarcasmo } \\
\text { e a ironia ao interagir } \\
\text { com falantes que aludem } \\
\text { situações passadas em } \\
\text { comum. }\end{array}$ & Adultos típicos & $\begin{array}{l}\text { Sentenças } \\
\text { positivas e } \\
\text { negativas }\end{array}$ & $\begin{array}{l}\text { Risada, prazer e } \\
\text { humor/ crítica, } \\
\text { deboche, } \\
\text { constrangimento }\end{array}$ & Compreensão \\
\hline $\begin{array}{l}\text { Kumon- } \\
\text { Nakamura, } \\
\text { Glucksberg, \& } \\
\text { Brown (1995) }\end{array}$ & 4 & $\begin{array}{l}\text { Testar a teoria alusiva que } \\
\text { afirma que as observações } \\
\text { irônicas têm seus efeitos } \\
\text { aludindo a uma expectativa } \\
\text { fracassada. }\end{array}$ & Adultos típicos & $\begin{array}{l}\text { Situações } \\
\text { cotidianas }\end{array}$ & $\begin{array}{l}\text { Convencimento } \\
\text { e atenção }\end{array}$ & Compreensão \\
\hline $\begin{array}{l}\text { Langdon, } \\
\& \text { Coltheart } \\
(2004)\end{array}$ & 36 & $\begin{array}{l}\text { Investigar se adultos } \\
\text { esquizotípicos apresentam } \\
\text { dificuldades de reconhecer } \\
\text { metáforas e ironias. }\end{array}$ & $\begin{array}{l}\text { Adultos } \\
\text { atípicos }\end{array}$ & $\begin{array}{l}\text { Sentenças } \\
\text { positivas }\end{array}$ & $\begin{array}{l}\text { Convencimento } \\
\text { e atenção }\end{array}$ & Compreensão \\
\hline $\begin{array}{l}\text { Li, Law, Lam, } \\
\& \text { To (2013) }\end{array}$ & 13 & $\begin{array}{l}\text { Investigar o uso de dicas } \\
\text { prosódicas na compreensão } \\
\text { de ironia em crianças de } \\
\text { língua cantonense com e sem } \\
\text { TEA. }\end{array}$ & $\begin{array}{l}\text { Crianças } \\
\text { atípicas/típicas }\end{array}$ & $\begin{array}{l}\text { Situações } \\
\text { cotidianas }\end{array}$ & $\begin{array}{l}\text { Convencimento } \\
\text { e atenção }\end{array}$ & Compreensão \\
\hline $\begin{array}{l}\text { Mo, Su, Chan, } \\
\text { \& Liu (2008) }\end{array}$ & 29 & $\begin{array}{l}\text { Explorar a compreensão } \\
\text { da metáfora e ironia na } \\
\text { esquizofrenia durante a } \\
\text { remissão e examinar o papel } \\
\text { do QI à luz da Teoria da } \\
\text { Mente. }\end{array}$ & $\begin{array}{l}\text { Adultos/ } \\
\text { atípicos }\end{array}$ & $\begin{array}{l}\text { Situações } \\
\text { cotidianas }\end{array}$ & $\begin{array}{l}\text { Convencimento } \\
\text { e atenção }\end{array}$ & Compreensão \\
\hline $\begin{array}{l}\text { Monetta, } \\
\text { Grindrod, \& } \\
\text { Pell (2009) }\end{array}$ & 11 & $\begin{array}{l}\text { Analisar um grupo de } \\
\text { pacientes com e sem } \\
\text { parkinson com relação à } \\
\text { capacidade de interpretar } \\
\text { intenções comunicativas } \\
\text { subjacentes à ironia verbal e } \\
\text { mentiras. }\end{array}$ & $\begin{array}{l}\text { Adultos } \\
\text { típicos/atípicos }\end{array}$ & $\begin{array}{l}\text { Situações } \\
\text { cotidianas }\end{array}$ & $\begin{array}{l}\text { Convencimento } \\
\text { e atenção }\end{array}$ & Compreensão \\
\hline $\begin{array}{l}\text { Nicholson, } \\
\text { Whalen, \& } \\
\text { Pexman (2013) }\end{array}$ & 30 & $\begin{array}{l}\text { Investigar se a apreciação e } \\
\text { o processamento da ironia } \\
\text { estão relacionados com } \\
\text { habilidades de acordo com } \\
\text { o sexo e se o processamento } \\
\text { da criança é maior do que } \\
\text { o sentido da fala que pode } \\
\text { explicar a Teoria Molecular } \\
\text { ou Interativa. }\end{array}$ & $\begin{array}{l}\text { Crianças } \\
\text { típicas }\end{array}$ & $\begin{array}{l}\text { Situações } \\
\text { cotidianas }\end{array}$ & $\begin{array}{l}\text { Convencimento } \\
\text { e atenção }\end{array}$ & $\begin{array}{l}\text { Compreensão/ } \\
\text { produção }\end{array}$ \\
\hline $\begin{array}{l}\text { Rapp, Langohr, } \\
\text { Mutschler, \& } \\
\text { Wild (2014) }\end{array}$ & 47 & $\begin{array}{l}\text { Investigar a compreensão } \\
\text { de ironia e de provérbio em } \\
\text { mulheres com esquizofrenia. }\end{array}$ & $\begin{array}{l}\text { Adultos } \\
\text { atípicos }\end{array}$ & $\begin{array}{l}\text { Sentenças } \\
\text { positivas e } \\
\text { negativas }\end{array}$ & $\begin{array}{l}\text { Crítica, } \\
\text { deboche e } \\
\text { constrangimento/ } \\
\text { risada, prazer e } \\
\text { humor }\end{array}$ & Compreensão \\
\hline
\end{tabular}




\begin{tabular}{|c|c|c|c|c|c|c|}
\hline Autores/ano & $\mathrm{N}$ & Objetivo geral & $\begin{array}{l}\text { Características } \\
\text { dos } \\
\text { participantes }\end{array}$ & $\begin{array}{c}\text { Tipo de } \\
\text { antecedente } \\
\left(\mathrm{S}^{\mathrm{D}}\right)\end{array}$ & Tipo de efeito & $\begin{array}{c}\text { Compreensão } \\
\text { ou produção } \\
\text { da ironia }\end{array}$ \\
\hline $\begin{array}{l}\text { Recchia, } \\
\text { Howe, Ross, } \\
\text { \& Alexander } \\
(2010)\end{array}$ & 39 & $\begin{array}{l}\text { Como crianças usam e } \\
\text { compreendem várias formas } \\
\text { de ironia em conversas } \\
\text { familiares positivas e } \\
\text { negativas. }\end{array}$ & $\begin{array}{l}\text { Crianças } \\
\text { típicas }\end{array}$ & $\begin{array}{l}\text { Sentenças } \\
\text { positivas e } \\
\text { negativas }\end{array}$ & $\begin{array}{l}\text { Risada, prazer e } \\
\text { humor/ crítica, } \\
\text { deboche, } \\
\text { constrangimento }\end{array}$ & $\begin{array}{l}\text { Compreensão/ } \\
\text { produção }\end{array}$ \\
\hline $\begin{array}{l}\text { Regel, } \\
\text { Coulson, \& } \\
\text { Gunter }(2010)\end{array}$ & 2 & $\begin{array}{l}\text { Analisar como e quando } \\
\text { os ouvintes compreendem } \\
\text { a ironia, tendo informação } \\
\text { extralinguística e linguística } \\
\text { do locutor. }\end{array}$ & Adultos típicos & $\begin{array}{l}\text { Sentenças } \\
\text { positivas }\end{array}$ & $\begin{array}{l}\text { Convencimento } \\
\text { e atenção }\end{array}$ & Compreensão \\
\hline $\begin{array}{l}\text { Spotorno, \& } \\
\text { Noveck (2014) }\end{array}$ & 42 & $\begin{array}{l}\text { Investigar se a compreensão } \\
\text { da leitura de histórias com } \\
\text { ironia demora mais para ser } \\
\text { processada do que as literais. }\end{array}$ & Adultos típicos & $\begin{array}{l}\text { Sentenças } \\
\text { positivas e } \\
\text { negativas }\end{array}$ & $\begin{array}{l}\text { Risada, prazer e } \\
\text { humor/ crítica, } \\
\text { deboche, } \\
\text { constrangimento }\end{array}$ & Compreensão \\
\hline $\begin{array}{l}\text { Stratta et al. } \\
(2007)\end{array}$ & 20 & $\begin{array}{l}\text { Explorar a apreciação da } \\
\text { ironia em pessoas com } \\
\text { esquizofrenia. }\end{array}$ & $\begin{array}{l}\text { Adultos } \\
\text { atípicos }\end{array}$ & $\begin{array}{l}\text { Sentenças } \\
\text { positivas }\end{array}$ & $\begin{array}{l}\text { Risada, prazer e } \\
\text { humor }\end{array}$ & $\begin{array}{l}\text { Compreensão/ } \\
\text { produção }\end{array}$ \\
\hline Yonge (2007) & 15 & $\begin{array}{l}\text { Investigar se a ironia } \\
\text { verbal é utilizada como } \\
\text { um comportamento } \\
\text { comunicativo proeminente } \\
\text { entre equipe e pacientes em } \\
\text { uma unidade de cuidados } \\
\text { psiquiátricos. }\end{array}$ & $\begin{array}{l}\text { Adolescentes } \\
\text { atípicos }\end{array}$ & $\begin{array}{l}\text { Situações } \\
\text { cotidianas }\end{array}$ & $\begin{array}{l}\text { Convencimento } \\
\text { e atenção/ } \\
\text { risada, prazer e } \\
\text { humor }\end{array}$ & $\begin{array}{l}\text { Compreensão/ } \\
\text { produção }\end{array}$ \\
\hline $\begin{array}{l}\text { Zalla, } \\
\text { Amsellem, } \\
\text { Chaste, Ervas, } \\
\text { Leboyer, \& } \\
\text { Champagne- } \\
\text { Lavau (2014) }\end{array}$ & 70 & $\begin{array}{l}\text { Investigar a existência de } \\
\text { dificuldades na compreensão } \\
\text { do discurso não literal, } \\
\text { como a ironia em pacientes } \\
\text { autistas. }\end{array}$ & $\begin{array}{l}\text { Adultos } \\
\text { atípicos }\end{array}$ & $\begin{array}{l}\text { Situações } \\
\text { cotidianas }\end{array}$ & $\begin{array}{l}\text { Convencimento } \\
\text { e atenção }\end{array}$ & Compreensão \\
\hline
\end{tabular}

\section{Estudar a ironia compreendida ou a produzida?}

Foram analisados 43 estudos dos quais 32 analisaram o comportamento verbal de compreensão da ironia pelo ouvinte, um (1) estudo analisou a produção de ironia e 10 estudos analisaram a tanto a compreensão quanto a produção da ironia. Tais dados sugerem que o papel do ouvinte (audiência) provavelmente é extremamente importante para a manutenção de um repertório verbal irônico. A audiência tem o papel de controlar o comportamento do falante por duas vias: a dos estímulos discriminativos não verbais (incluindo o corpo do ouvinte e suas ações não verbais) e a dos estímulos discriminativos verbais. Como afirmou Skinner (1957), audiências diferentes podem controlar diferentes repertórios verbais. Isso significa que a probabilidade de um comportamento verbal irônico ser emitido e a maneira como ele será emitido, ou seja, sua topografia e função (se como humor, sarcasmo, sátira), dependerão das características da audiência na relação com o falante. A isso Skinner deu o nome de audiência múltipla, conceito-chave da definição skinneriana de ironia (Messa et al., 2014). 
Diferentes audiências/ouvintes (como "causas" ou funções diferentes) geram diferentes tipos de repertório verbal irônico: na presença de uma criança, um adulto pode emitir um comportamento verbal irônico com função de produzir riso na criança (isso vai depender do quanto o falante conhece a criança, e se já foi irônico antes com essa criança, e finalmente, se sua ironia foi reforçada por ela); na presença de um estagiário que acabara de entrar na empresa, um adulto pode emitir uma ironia sarcástica para seus antigos colegas de trabalho, com a função de debochar do estagiário (isso pode significar que a ironia emitida pelo falante é direcionada aos colegas de trabalho e também depende do conhecimento e do reforço prévios que dão sentido ao episódio verbal).

O objeto de estudo "compreensão da ironia pelo ouvinte" nas investigações empíricas revisadas, em sua maioria, tem relação com o conceito comportamental de ironia centrado no conceito de audiência múltipla (Messa et al., 2014). Ela é parte essencial para a compreensão de um episódio verbal total irônico, uma vez que nele tem-se um ouvinte que faz parte da comunidade verbal do falante (não somente no sentido linguístico, mas também no sentido de conhecer as contingências que favoreceram a emissão da ironia) e outro que seria a "vítima" da ironia. Quanto a isso, os estudos de Kreuz, \& Gluksberg (1989), Ishida, \& Abe (2010) e Anolli et al. (2000) demonstram que, para o irônico, "vitimar" alguém pode eliciar prazer (especialmente se a ironia emitida gerar um ambiente reforçador de "vitória" sobre a "vítima") e, para o ouvinte, pode gerar constrangimento (caso a consequência da ironia seja um desconforto além do previsto). Assim como afirmado por Skinner (1991), o falante não é quem inicia o episódio verbal; antes, deve haver um ouvinte e esse ouvinte é o responsável pelo comportamento do falante, mesmo quando esse ouvinte é o próprio falante (como ouvinte de si mesmo ou seu próprio ouvinte). Por isso, analisar o comportamento do ouvinte é essencial para compreensão do comportamento do falante; ou seja, compreender o que os ouvintes fazem levará à compreensão do porquê os falantes se comportam de determinada maneira, seja ela irônica ou não.

O tipo de estímulo antecedente utilizado nos estudos revisados pode ser verificado na tabela 1 (Coluna 5). Em 12 estudos, esses estímulos foram apenas sentenças "positivas" (que incluíam ironia com função de humor e com função de apenas dizer o contrário dos fatos, a ironia pura). Em nove deles, utilizaram-se tanto sentenças "positivas" quanto "negativas" (que incluíam deboche e sarcasmo: função de ridicularização com escarnecimento e crueldade, respectivamente). Por fim, 21 estudos apresentaram situações cotidianas (histórias; e não apenas sentenças isoladas) com ironia com função de humor e de apenas dizer o contrário dos fatos (ironia pura).

A especificação desses antecedentes reforça a premissa de que todo comportamento verbal, ainda que seja emitido apenas no nível privado, tem sua origem no ambiente e modifica esse ambiente. Assim, de acordo com os princípios da análise do comportamento (cf. Skinner, 1957), a comunidade verbal instala e mantém os comportamentos verbais irônicos do falante por processos básicos de aprendizagem: reforço, discriminação, modelagem, imitação etc. Entre os 42 estudos analisados, verificou-se, por exemplo, maior aceitação por parte do ouvinte nas situações em que a ironia emitida tinha função de humor do que naquelas que envolviam emissão de ironia com função de deboche (Calmus, \& Caillies, 2014; Dews et al., 1996; Yonge, 2007); e em alguns artigos (e.g., Akimoto, \& Miyazawa, 2011; Amenta et al., 2013) foram registrados padrões mais confortáveis de comportamento emocional nos ouvintes da ironia (i. e., os participantes riram e afirmaram ter experimentado sentimentos positivos). Diferentemente, os ambientes que mostraram a ironia emitida com tom de deboche, sarcasmo ou crítica eliciaram sentimentos relatados como aversivos (e.g., raiva, angústia) e evocaram descrições do irônico como 
cínico (Blaser, 1976; Glenwright, \& Pexman, 2010; Kreuz, \& Glucksberg, 1989). Isso evidencia que a história de reforço do ouvinte pode fazer com que ele sinta como reforçador ou aversivo os ambientes com estímulos verbais irônicos, a depender se a ironia for "positiva" ou "negativa" em relação a sua história de reforço e às operações motivacionais do momento.

Essa evidência dos efeitos "positivos" ou "negativos" da ironia (humor, riso, crítica, deboche, constrangimento, raiva) aparece especialmente no estudo de Recchia et al. (2010), que observaram os comportamentos das crianças ao compreenderem e emitirem ironia em conversas familiares. Os comportamentos verbais irônicos emitidos pelos pais apareceram em contextos reforçadores (harmônicos) e aversivos (conflituosos). Nos contextos conflituosos (e. g., quando uma criança emitia comportamento emocional de teimosia), as mães foram mais propensas a fazerem perguntas retóricas e a emitirem ironias; e os pais, a emitirem comportamentos irônicos mais sob a forma de hipérboles (isto é, exageravam ao comunicarem uma ideia com finalidade expressiva), eufemismos (isto é, emitiam expressão ou locução mais agradável em vez de palavras que poderiam soar grosseiras) ou perguntas retóricas (isto é, perguntas mais eloquentes). Os filhos também apresentaram evidências de uma crescente capacidade de emitir comportamentos verbais irônicos, especialmente com topografias de hipérbole e de perguntas retóricas. Finalmente, seus irmãos mais velhos demonstraram compreender melhor a ironia do que os mais novos, confirmando mais uma vez a importância da história de reforço na relação com a comunidade verbal para que repertórios mais refinados de compreensão da ironia sejam adquiridos.

No geral, acerca da compreensão ou produção da ironia, os resultados dos estudos de revisão sugerem que as conversas em casa entre os membros da família podem ser contextos importantes para o desenvolvimento da produção e compreensão do comportamento verbal irônico pelas crianças. Isso mostra que a comunidade verbal próxima da criança é capaz de modelar desde cedo o comportamento de falante e de ouvinte relacionados à ironia.

\section{Quem eram os participantes do estudo?}

A tabela 1 permite verificar que 27 estudos foram realizados com adultos (homens e mulheres) acima de 18 anos, com desenvolvimento típico; em segundo lugar $(n=6)$ foram os estudos com adultos com algum diagnóstico de transtorno mental (esquizofrenia/demência/amnésia/Parkinson/ abuso de álcool); crianças com desenvolvimento típico foram participantes em sete estudos; crianças com desenvolvimento atípico, especialmente o Transtorno do Espectro Autista (TEA), em quatro estudos; e, por fim, adolescentes foram os participantes de dois estudos. É importante analisar quem foram os participantes das pesquisas, uma vez que suas características ajudarão a identificar e compreender parte das consequências da ironia obtidas nos estudos. Esses tipos variados de participantes eram ora falantes irônicos (produção) ora ouvintes de ironias (compreensão).

Em estudos como os de Stratta et al. (2007), Mo et al. (2008), Amenta et al. (2013), Zalla et al. (2014) e Rapp et al. (2014), em que os participantes eram adultos/crianças com diagnóstico de transtorno psicológico (i.e., TEA, Esquizofrenia), as conclusões foram que a compreensão da ironia era reduzida. Apesar de fazerem parte da comunidade verbal do irônico ou terem intimidade com ele, os portadores desses transtornos pareceram estar psicobiologicamente limitados ou impedidos de compreender a ironia. Os autores não souberam interpretar o porquê disto, mas, talvez isso se deva ao fato de a ironia ser um comportamento verbal complexo que, em sua base de definição linguística (Paiva, 1961), envolve o que não pode ser tateado no ambiente, como o contrário do que é verbalizado (que, por sua vez, já é um estímulo arbitrário). 
Quanto à idade da aprendizagem da ironia, os estudos com crianças (Dews et al., 1996; Glenwright \& Pexman, 2010; Filippova \& Astington, 2008; Recchia et al., 2010) demonstram que a compreensão da ironia começa a ser modelada entre os 5 e 6 anos de idade. Nessa faixa etária, alguns tipos de ironia são mais facilmente compreendidos do que outros. As ironias com função de ridicularizar, como as satíricas e sarcásticas, não são tão bem compreendidas pelas crianças quanto o são as puras e as com função de humor. Conforme esses autores relataram, quanto maior a idade da criança (com desenvolvimento típico) melhor foi sua compreensão e sua percepção das diferentes funções da ironia. Essas informações são importantes uma vez que o desenvolvimento do repertório irônico, por ser complexo, necessita, pelo falante e pelo ouvinte, de contingências especiais de aquisição e manutenção com relação à sua emissão e compreensão. Se porventura uma criança cresce em um ambiente pobre de estimulação verbal irônica, provavelmente ela terá dificuldade em compreender ironias e, consequentemente, emiti-las em ambientes similares ou não. Assim, os estudos citados permitem afirmar que a capacidade de compreender ironia aumenta com a idade e o repertório verbal irônico emitido é construído na proporção desse aumento, no contato com a comunidade verbal.

\section{Ser irônico para quê?}

$\mathrm{Na}$ Coluna 6 da tabela 1 pode-se observar o tipo de função/efeito (consequências) que os estudos revisados descreveram com relação à compreensão e à produção da ironia: efeito (consequência) da ironia no ouvinte e os estímulos antecedentes relacionados com a função da emissão da ironia pelo falante. Os resultados foram agrupados em três categorias: (a) convencimento e/ou atenção, contabilizando um total de 24 estudos; (b) risos, sensação de prazer ou humor, com um total de 22 estudos; e (c) crítica, deboche ou constrangimento, com um total de 10 estudos.
Os pensamentos e sentimentos foram tipos de função/efeito comuns (consequências) da ironia, dentre as descrições dos estudos revisados. Essas consequências envolvem o reforço do convencimento e da atenção do ouvinte, que é a função predominante da ironia. Segundo Kumon-Nakamura et al. (1995), o falante emite ironia com a intenção de obter a atenção do ouvinte, ainda que o ouvinte não responda de acordo com a expectativa do falante. Frustrar o ouvinte não reduz a probabilidade de emissão da ironia pelo falante e nem o valor do reforço dessa emissão; aliás, a produção da frustração do ouvinte pode ser uma das funções do comportar-se ironicamente.

A relação da ironia com os consequentes riso e humor também fez parte de uma quantidade expressiva de estudos (22). O humor apresenta características similares à ironia com relação à causação múltipla e audiência múltipla e, conforme afirmaram Hübner et al. (2005), ele também é um comportamento adaptativo, uma vez que pode ser emitido com a função de mudar as propriedades estressoras de um ambiente tornando-as mais amenas (como quando se diz que o falante "leva a vida na esportiva"). No estudo com adolescentes desenvolvido por Yonge (2007), a ironia emitida com função de humor apresentou propriedades interessantes que corroboraram essa conclusão de Hübner et al. (2005), em que comportamentos verbais não literais com função de humor promovem um ambiente mais reforçador, solidário e contribuinte da melhoria da autoestima. O repertório irônico dos adolescentes teve as funções de esquiva ("defesa") de ambientes aversivos ou de reforço positivo ("integração") da aproximação de ambientes sociais desejáveis.

Entre os estudos revisados de ironia com função de crítica e deboche, o de Glenwright e Pexman (2010) demonstrou que crianças por volta dos seis anos de idade conseguem compreender o significado não literal da ironia e do sarcasmo, porém não têm repertório comportamental suficiente, enquanto audiência, para distinguir os "fins pragmáticos" do 
falante: a função do comportamento verbal irônico emitido. Os estudos revisados mostram que, para ser uma audiência qualificada para um irônico, como afirmou Skinner (1957), o ouvinte precisa fazer parte da comunidade verbal do irônico, ou pelo menos ter experimentado uma parcela de variáveis dessa comunidade para que ele possa compreender o significado (função) ironia emitida por ele.

\section{Conclusão}

Respondendo ao seu objetivo, o presente estudo demonstrou que os estudos empíricos da ironia apontam quatro elementos a serem considerados em pesquisas experimentais ou análises funcionais da ironia por analistas do comportamento. Primeiro, apontam para o indivíduo que se comporta (o quem; o irônico ou o ouvinte dele): nos estudos analisados, esse dado refere-se aos participantes dos estudos, ou seja, as crianças e os adultos típicos e atípicos; e ao comportamento dos ouvintes que eram foco da maior parte dos estudos. Segundo, apontam para o objeto-foco de análise (o quê; a ironia produzida ou a compreendida): os estudos demonstraram uma maior tendência a analisar a compreensão da ironia em adultos e crianças, sendo que a produção da ironia foi analisada, em sua maior parte, nas crianças atípicas. Esse foco na compreensão verbal é relevante ao programa de pesquisa lançado por Skinner, que enfatizou a produção verbal. Terceiro, apontam para a função do comportamento (o para quê: efeitos ou consequências da ironia) demonstrada nos estudos como convencimento e atenção, risada, prazer e humor e crítica, deboche e constrangimento. Esses dados foram discutidos em nível interpretativo por Skinner. Quarto, indicam operacionalmente o ambiente no qual o irônico se comporta (o onde: contexto): ambientes familiares e não familiares (ambientes experimentais com pessoas conhecidas e desconhecidas, em clínicas e grupos de reabilitação, com possibilidade de observação in loco).
A identificação desses itens nos estudos revisados demonstra que eles podem ser considerados relevantes para uma análise funcional da ironia, uma vez que avaliam empiricamente o ambiente de ocorrência da ironia e a função que o comportamento irônico tem neste ambiente. Assim, os requisitos básicos para a análise funcional (Skinner, 1957) puderam ser vistos nos estudos revisados.

Nessa análise funcional empírica do comportamento irônico, o pesquisador deve estar atento às características: (a) dos antecedentes que contribuem para a emissão de ironia (nos estudos foram apresentados estímulos antecedentes em forma de sentenças irônicas positivas e negativas e histórias cotidianas com enredo irônico); (b) das variáveis ambientais das quais o comportamento irônico é função (os ambientes analisados foram tanto experimentais quanto naturais, com participantes que se conheciam e não se conheciam, ou familiares e não familiares); (c) das consequências do comportamento verbal irônico geradas no ouvinte e no falante do comportamento verbal irônico (produzidas por respostas emitidas em conjunto com variáveis ambientais que, nos estudos revisados, foram variáveis com funções na geração de convencimento, humor e crítica); e (d) dos integrantes do episódio verbal irônico: falante, ouvinte, ouvinte qualificado e ouvinte não qualificado (isto é, se os ouvintes fazem ou não fazem parte da mesma comunidade verbal dos falantes, respondendo adequadamente ou não, ao contexto irônico).

Os resultados apresentados pelos estudos demonstram que tanto adultos quanto crianças típicas compreendem melhor a ironia em ambientes familiares do que os(as) atípicas; e que tanto adultos quanto crianças atípicas apresentam dificuldades ou até mesmo impedimentos para compreender a ironia, tanto na forma falada quanto na forma escrita. Nos contextos em que a ironia é frequentemente utilizada pelos adultos, as crianças apresentaram maior tendência a emitir frases irônicas.

Espera-se que a descrição de elementos empíricos para uma análise funcional do comportamento 
verbal irônico feita no presente estudo contribua para o aprimoramento do conhecimento desse comportamento e para a execução de pesquisas experimentais sobre o mesmo no campo da análise do comportamento. Nessa execução, a análise funcional do comportamento verbal irônico deve passar por todas as etapas de uma análise funcional tradicional, permitindo compreender ainda mais que a ironia é comportamento operante e a explicação da sua função depende de variáveis ambientais específicas, algumas identificadas e isoladas experimentalmente em estudos realizados em outras áreas; e que comportamento verbal irônico é desenvolvido no repertório do indivíduo quando ele vivencia contingências que favorecem sua aquisição e manutenção. A ironia também é compreendida como um comportamento verbal adaptativo; e pode ser emitida com várias funções, do deboche e constrangimento ao riso e humor.

Os estudos revisados mostraram como manipular empiricamente algumas das diferentes nuances da ironia (humor, sarcasmo, cinismo, deboche e outras, e suas combinações). Nesse aspecto, eles podem ser relevantes para a análise comportamental da ironia, considerando as variáveis ambientais controladoras dessas nuances. Conforme demonstraram Messa et al. (2014), o grande desafio será construir ambientes experimentais com uma audiência múltipla, que de modo preditivo e criativo, possa controlar a emissão dessas nuances. Na descrição da função dessa audiência múltipla está a maior contribuição da análise do comportamento ao estudo da ironia verbal. Os estudos revisados podem futuramente potencializar ainda mais tal contribuição.

\section{Referências}

Akimoto, Y., \& Miyazawa, S. (2011). What factors play a role in a listener's feelings evoked by irony?: The effect of listeners' personality traits and relationship with the speaker. Shinrigaku Kenkyu, 82(4), 370-378. https://doi.org/10.4992/jjpsy.82.370
Amenta, S., Noël, X., Verbanck, P., \& Campanella, S. (2013). Decoding of emotional components in complex communicative situations (irony) and its relation to empathic abilities in male chronic alcoholics: An issue for treatment. Alcohol Clinic Experimental Research, 37, 339-347. https:// doi.org/10.1111/j.1530-0277.2012.01909.x

Anastácio-Pessana, F. L., Almeida-Verdu, A. C. M., Bevilacqua, M. C., \& Souza, D. G. (2015). Usando o paradigma de equivalência para aumentar a correspondência na fala de crianças com implante coclear na nomeação de figuras e na leitura. Psicologia: Reflexão e Crítica, 28, 365-377. https://doi.org/10.1590/1678-7153.201528217

Angeleri, R., \& Airenti, G. (2014). The development of joke and irony understanding: A study with 3- to 6-year-old children. Canadian Journal of Experimental Psychology, 68, 133-146. https:// doi.org/10.1037/0012-1649.17.4.472

Anolli, L., Ciceri, R., \& Infantino, M. G. (2000). Irony as a game of implicitness: Acoustic profiles of ironic communication. Journal of Psycholinguist Research, 29, 275-311. https://doi. org/10.1023/A:1005100221723

Baptista, N., Macedo, E. C., \& Boggio, P. S. (2015). Looking more and at different things: Differential gender eye-tracking patterns on an irony comprehension task. Psychology \& Neuroscience, 8, 157-167. https://doi.org/10.1037/h0101061

Blaser, A. (1976). Irony and cynicism as forms of defense. Confined Psychiatric Journal, 19, 8088. Recuperado de https://www.ncbi.nlm.nih. gov/pubmed/1024012

Brait, B. (1996). Ironia em perspectiva polifônica. Campinas: Unicamp.

Brum, Z. P., \& Siniak, D. S. (2011). A gíria: a comunicação de adolescentes usuários de substâncias psicoativas. Revista de Enfermagem da UFSM, 1 , 403-411. https://doi.org/10.5902/217976923556

Bruntsch, R., \& Ruch, W. (2017a). The role of humor-related traits and broad personality dimensions in irony use. Personality and Individual Differences, 112, 139-143. https://doi.org/10.5902/217976923556 
Bruntsch, R., \& Ruch, W. (2017b). Studying irony detection beyond ironic criticism: Let's include ironic praise. Frontiers in Psychology, 8, 1-15. https://doi.org/10.3389/fpsyg.2017.00606

Caillies, S., Bertot, V., Motte, J., Raynaud, C., \& Abely, M. (2014). Social cognition in ADHD: Irony understanding and recursive theory of mind. Research in Developmental Disabilities, 35, 3191-3198. https://doi.org/10.1016/j. ridd.2014.08.002

Caillies, S., Hody, A., \& Calmus, A. (2012). Theory of mind and irony comprehension in children with cerebral palsy. Research Development Disabilities, 33, 1380-1388. https://doi. org/10.1016/j.ridd.2012.03.012

Calmus, A., \& Caillies, S. (2014). Verbal irony processing: How do contrast and humour correlate? International Journal of Psychology, 49, 46-50. https://doi.org/10.1002/ijop.12003

Cornejol, C., Simonetti, F., Aldunate, N., Ibáñez, A., López, V., \& Melloni L. (2007). Electrophysiological evidence of different interpretative strategies in irony comprehension. Journal of Psycholinguist Research, 36, 411-430. https:// doi.org/10.1007/s10936-007-9052-0

Deliens, G., Stercq, F., Mary, A., Slama, H., Cleeremans, A., Peigneux, P., \& Kissine, M. (2015). Impact of acute sleep deprivation on sarcasm detection. PloS ONE, 10, 1-19. https://doi. org/10.1371/journal.pone.0140527

Demo, P. (2000). Metodologia do conhecimento científico. São Paulo: Atlas.

Dennis, M., Simic, N., Agostino, A., Taylor, G., Bigler, E. D., Rubin, K., ... Yeates, K. O. (2012). Irony and empathy in children with traumatic brain injury. Journal of the International. Neuropsychological Society, 19, 1-11. https://doi. org/10.1017/S1355617712001440

Dews, S., Winner, E., Kaplan, J., Rosenblatt, E., Hunt, M., Lim, K., ... Smarsh, B. (1996). Children's understanding of the meaning and functions of verbal irony. Child Development, 67(6), 3071-3085. https://doi.org/10.1111/j.1467-8624.1996.tb01903
Eikeseth, S., \& Smith, D. P. (2013). An analysis of verbal stimulus control in intraverbal behavior: Implications for practice and applied research. The Analysis of Verbal Behavior, 29, 125-135. https://doi.org/10.1007/BF03393130

Filik, R., Hunter, C. M., \& Leuthold, H. (2015). When language gets emotional: Irony and the embodiment of affect in discourse. Acta Psychologica, 156, 114125. https://doi.org/10.1016/j.actpsy.2014.08.007

Filik, R., Leuthold, H., Wallington, K., \& Page, J. (2014). Testing theories of irony processing using eye-tracking and ERPS. Journal of Experimental Psychology Learning Memory and Cognition, 40, 811-828. https://doi.org/10.1037/a0035658

Filik, R., Țurcan, A., Thompson, D., Harvey, N., Davies, H., \& Turner, A. (2016). Sarcasm and emoticons: Comprehension and emotional impact. The Quarterly Journal of Experimental Psychology, 69, 2130-2146. https://doi.org/1 0.1080/17470218.2015.1106566

Filippova, E. \& Astington, J. W. (2008). Further development in social reasoning revealed in discourse irony understanding. Child Development, 79, 126-138. https://doi.org/10.1111/j.14678624.2007.01115.x

Filippova, E., \& Astington, J. W. (2010). Children's understanding of social-cognitive and social-communicative aspects of discourse irony. Children Development, 81, 913-928. https://doi. org/10.1111/j.1467-8624.2010.01442.x

Gaudreau, G., Monetta, L., Macoir, J., Laforce, R., Poulin, S., \& Hudon, C. (2013). Verbal irony comprehension in older adults with amnestic mild cognitive impairment. Neuropsychology, 27, 702-712. https://doi.org/10.1037/a0034655

Glenwright, M., \& Pexman, P. M. (2010). Development of children's ability to distinguish sarcasm and verbal irony. Journal of Child and Language, 37(2), 429-451. https://doi.org/10.1017/ S0305000909009520

González-Fuente, S., Escandell-Vidal, V., \& Prieto P. (2015). Gestural codas pave the way to the understanding of verbal irony. Journal of Prag- 
matics, 90, 26-47. https://doi.org/10.1016/j. pragma.2015.10.002

Gross A. C., Fuqua R. W., \& Merritt T. A. (2013). Evaluation of verbal behavior in older adults. The Analysis of Verbal Behavior, 29, 85-99. https://doi.org/10.1076/clin.13.3.359.1742

Hanke, M., \& Ibe, P. (2016). Lies, irony, and contradiction - an annotation of semantic conflict in the movie "Forrest Gump". F1000Research, 5, 1-8. https://doi.org/10.12688/f1000research.9635.1

Hübner, M. M. C., Austin, J., \& Miguel, C. F. (2008). Effects of praising qualifying autoclitics on the frequency of reading. The Analysis of Verbal Behavior, 24, 55-62. https://doi.org/10.1007/ BF03393056

Hübner, M. M. C., Miguel, C. F., \& Michael, J. (2005). Controle múltiplo no comportamento verbal: humor brasileiro e operantes relacionados. Revista Brasileira de Análise do Comportamento, 1,1-14. https://doi.org/10.18542/rebac.v1i1.673

Hur, M., \& Caixeta, L. (2013). Non-literal language and semantic dementia. Dementia Neuropsycholy, 7, 424-427. https://doi.org/10.1590/ S1980-57642013DN74000011

Ishida, Y., \& Abe, J. (2010). Is the victim of irony identified by echoic mention? Shinrigaku Kenkyu, 80, 485-93. https://doi.org/10.4992/jjpsy.80.485

Jacob, H., Kreifelts B., Nizielski S., Schütz A., \& Wildgruber D. (2016). Effects of emotional intelligence on the impression of irony created by the mismatch between verbal and nonverbal cues. PLoS ONE, 11(10), 1-17. https://doi. org/10.1371/journal.pone.0163211

Jorgensen, J., Miller G. A., \& Sperber, D. (1984). Test of the mention theory of irony. Journal of Experimental Psychology, 113, 112-120. https:// doi.org/10.1037/0096-3445.113.1.112

Kisamore, A. N., Karsten, A. M., Mann, C. C., \& Conde, K. A. (2013). Effects of a differential observing response on intraverbal performance of preschool children: A preliminary investigation. The Analysis of Verbal Behavior, 29(1), 101-108. https://doi.org/10.1007/BF03393127
Koehler-Platten, K., Grow, L. L., Schulze, K. A., \& Bertone, T. (2013). Using a lag reinforcement schedule to increase phonemic variability in children with autism spectrum disorders. The Analysis of Verbal Behavior, 29, 71-83. https:// doi.org/10.1007/BF03393125

Kreuz, R. J., \& Link, K. E. (2002). Asymmetries in the use of verbal irony. Journal of Language and Social Psychology, 21, 127-143. https:// doi.org/127-14310.1177/02627X02021002002

Kreuz, R. J., \& Glucksberg, S. (1989). How to be sarcastic: The echoic reminder theory of verbal irony. Journal of Experimental Psychology: General, 118, 374-386. https://doi. org/10.1037/0096-3445.118.4.374

Kumon-Nakamura, S., Glucksberg, S., \& Brown, M. (1995). How about another piece of pie: The allusional pretense theory of discourse irony. Journal of Experimental Psychology General, 124, 3-21. https://doi.org/10.1037//0096-3445.124.1.3

Langdon, R., \& Coltheart M. (2004). Recognition of metaphor and irony in young adults: The impact of schizotypal personality traits. Psychiatry Research, 30, 9-20. https://doi.org/10.1016/j. psychres.2003.10.005

Li, J. P., Law, T., Lam, G. Y., \& To, C. K. (2013). Role of sentence-final particles and prosody in irony comprehension in cantonese-speaking children with and without Autism Spectrum Disorders. Clinical Linguistics e Phonetics, 27, 18-32. https://doi.org/10.3109/02699206.2012.734893

Machado, I. L. (1995). A ironia como fenômeno linguístico-argumentativo. Revista de Estudos Linguísticos, 2, 143-155. https://doi. org/10.17851/2237-2083.3.2.141-153

Messa, L. C. S., Borloti, E., \& Carmelino, A. C. (2014). Linguistics and behavior analysis in the functional conceptualization of verbal irony. European Journal of Child Development, Education and Psychopathology, 2, 97-121. https://doi.org/10.30552/ejpad.v2i3

Mo, S., Su, Y., Chan, R. C., \& Liu, J. (2008). Comprehension of metaphor and irony in schizophrenia 
during remission: The role of theory of mind and IQ. Psychiatry Research, 15, 21-29. https:// doi.org/10.1016/j.psychres.2006.04

Monetta, L., Grindrod, C. M., \& Pell, M. D. (2009). Irony comprehension and theory of mind deficits in patients with Parkinson's disease. Cortex, 45, 972981. https://doi.org/10.1016/j.cortex.2009.02.021

Mussi, S. V., Soares, M. R. Z., \& Grossi, R. (2013). Transtorno bipolar: avaliação de um programa de psicoeducação sob o enfoque da análise do comportamento. Revista Brasileira de Terapia Comportamental e Cognitiva, 15(2), 45-63. https://doi.org/10.31505/rbtcc.v15i2.602

Nicholson, A., Whalen, J., M., \& Pexman, P. M. (2013). Children's processing of emotion in ironic language. Frontiers in Psychology, 4, 1-10. https://doi.org/10.3389/fpsyg.2013.00691

Nishiwaki, S. (2015). Análise argumentativa da ironia standard e da ironia não-standard. Letras de Hoje, 50, 287-293. https://doi.org/10.15448/19847726.2015 .3 .21123

Paiva, M. H. N. (1961). Contribuição para uma estilística da ironia. Lisboa: Fundação Calouste Gulbenkian.

Pezzato, F. A., Brandão, A. S., \& Oshiro, C. K. B. (2012). Intervenção baseada na psicoterapia analítica funcional em um caso de transtorno de pânico com agorafobia. Revista Brasileira de Terapia Comportamental e Cognitiva, 14, 74-84. https://doi.org/10.31505/rbtcc.v14i1.495

Rapp, A. M., Langohr, K., \& Mutschler, D. E., \& Wild, B. (2014). Irony and proverb comprehension in schizophrenia: Do female patients "dislike" ironic remarks? Schizophrenia Research and Treatment, 1-11. https://doi. org/10.1155/2014/841086

Recchia, H. E., Howe, N., Ross, H. S., \& Alexander, S. (2010). Children's understanding and production of verbal irony in family conversations.
Journal of Development Psychology, 28, 25574. https://doi.org/10.1348/026151008X401903 Regel, S., Coulson, S., \& Gunter, T. C. (2010). The communicative style of a speaker can affect language comprehension? ERP evidence from the comprehension of irony. Brain Research, 1311, 121-135. https://doi.org/10.1016/j.brainres.2009.10.077

Silva, A. V., Todorov, J. C., \& Silva, R. L. F. C. (2012). Cultura organizacional: a visão da análise do comportamento. Revista Brasileira de Terapia Comportamental e Cognitiva, 14, 48-63. https:// doi.org/10.31505/rbtcc.v14i2.507

Skinner, B. F. (1974/2003). Sobre o behaviorismo (M. da P. Villalobos trad.). São Paulo: Cultrix. Skinner, B. F. (1957). Verbal Behavior. New York: Applenton-Century-Crofts.

Skinner, B. F. (1991). Questões recentes na Análise do Comportamento (A. L. Néri, Trad.). Campinas: Papirus. (Publicado originalmente em 1989).

Spotorno, N., \& Noveck, I. A. (2014). When is irony effortful? Journal of Experimental Psychology: General, 143(4), 1649-1665. https://doi. org/10.1037/a0036630

Stratta, P., Riccardi, I., Mirabilio, D., Di Tommaso, S., Tomassini,A., \& Rossi, A. (2007). Exploration of irony appreciation in schizophrenia: A replication study on an Italian sample. European Archieve of Psychiatry and Clinic Neuroscience, 257(6), 337339. https://doi.org/10.1163/22134379-17201006 Yonge, O. (2007). The power of irony in an adolescent residential psychiatric program. Journal of Psychosocial Nursing Mental Health Service, 45, 46-52.

Zalla, T., Amsellem, F., Chaste, P., Ervas, F., Leboyer, M., \& Champagne-Lavau, M. (2014). Individuals with autism spectrum disorders do not use social stereotypes in irony comprehension. PLoS ONE, 9(4), 1-9. https://doi.org/10.1371/journal. pone. 0095568
Recebido: dezembro 6, de 2017 Aprovado: agosto 2, de 2019 